\title{
Bundling Interventions to Enhance Pain Care Quality (BITE Pain) in Medical Surgical Patients
}

\author{
Karen L. Rice, DNS, APRN, ACNS-BC, ${ }^{1}$ Julie Castex, MSN, APRN, ACNS-BC, ${ }^{1}$ Margaret Redmond, MN, APRN, \\ ACNS-BC, ${ }^{2}$ Jeffrey Burton, PhD, ${ }^{3}$ Jia-Wen Guo, PhD, RN, ${ }^{4}$ Susan L. Beck, PhD, APRN, FAAN ${ }^{4}$ \\ ${ }^{1}$ Center for Nursing Research, Ochsner Clinic Foundation, New Orleans, LA ${ }^{2}$ Palliative Medicine, Ochsner Clinic Foundation, New Orleans, \\ LA ${ }^{3}$ Center for Outcomes and Health Services Research, Ochsner Clinic Foundation, New Orleans, LA ${ }^{4}$ College of Nursing, University of \\ Utah, Salt Lake City, UT
}

Background: Inadequate pain management and undertreatment remain a serious clinical issue among hospitalized adults, contributing to chronic pain syndromes and opioid dependency. Implementation of individual pain care interventions has been insufficient to improve pain care quality. The purpose of this interprofessional, patient-centered project was to implement a 6component bundle of evidence-based pain management strategies to improve patients' perception of pain care quality and 24-hour pain experience outcomes.

Methods: A quasi-experimental design was used to test the effect of a bundled pain management intervention on 3 medical surgical units. Baseline outcomes using the Pain Care Quality-Interdisciplinary (PainCQ- $-^{\circ}$ ) and Pain Care Quality-Nursing $\left(\right.$ PainCQ- $\mathrm{N}^{\odot}$ ) surveys were measured monthly for 4 months preintervention and 30 months postintervention.

Results: A convenience sample of 846 patients was analyzed. The effect of the intervention on pain outcomes could not be tested because unit-based adherence did not meet the goal of $80 \%$. A subsample of $70.2 \%$ (594/846) of participants was sufficient to complete a 3-group analysis of preintervention and postintervention participants with confirmed intervention adherence. Participants in the postintervention group who received all 6 components $(n=65)$ had significantly higher odds of higher PainCQ ${ }^{\odot}$ scores than those in the preintervention group $\left(n=141\right.$ ) (PainCQ- ${ }^{\odot}$ : odds ratio [OR] 2.61, 95\% confidence interval $[\mathrm{CI}] 1.54-4.42 ; \mathrm{PainCQ}-\mathrm{N}^{\odot}$ : OR $3.82,95 \% \mathrm{Cl} 2.06-7.09)$ or those in the postintervention group receiving $\leq 5$ components $(\mathrm{n}=388)\left(\mathrm{PainCQ}-\mathrm{I}^{\odot}: \mathrm{OR} 2.52,95 \% \mathrm{Cl}\right.$ 1.57-4.03; PainCQ-N ${ }^{\odot}$ : OR 3.84, 95\% Cl 2.17-6.80).

Conclusion: Medical surgical patients participating in this study who received the bundled 6-component intervention reported significantly higher levels of perceived pain care quality, suggesting that a bundled approach may be more beneficial than unstandardized strategies.

Keywords: Acute pain, animal assisted therapy, aromatherapy, implementation science, interprofessional relations, music therapy, pain-postoperative, pain management, pain measurement, quality indicators-health care, quality of health care, surveys and questionnaires

Address correspondence to Karen L. Rice, DNS, APRN, ACNS-BC, Center for Nursing Research, Ochsner Clinic Foundation, 1514 Jefferson Hwy., New Orleans, LA 70121. Tel: (504) 343-3688. Email: karen.rice53@gmail.com

\section{INTRODUCTION}

Pain in the United States is a public health crisis of epidemic proportions. ${ }^{1}$ Approximately 100 million Americans suffer from acute and chronic pain at an annual cost reaching $\$ 635$ billion, more than the combined healthcare expenditures for diabetes, cardiovascular disease, and cancer. ${ }^{2}$ Pain management is widely accepted as an important component of high-quality care and a strong contributor to patient satisfaction. ${ }^{3-5}$ Despite awareness and therapeutic improvements, inadequate pain management and undertreatment of pain remain a serious clinical issue among hospitalized patients, contributing to chronic pain syndromes and opioid dependency. ${ }^{6,7}$ Clearly, implementation of individual pain care interventions has been insufficient to improve patients' perceptions of pain care quality. ${ }^{8-11}$ Therefore, there is a need to implement an innovative pain management intervention that (1) actively engages the patient as a partner rather than a passive recipient of treatment; (2) applies bundled interventions that are complementary and conceptually aligned; and (3) improves patients' ability to cope with pain by providing some predictability and engaging them in control regarding the plan of care. ${ }^{12,13}$

\section{LITERATURE REVIEW}

A review of the published literature cited in Ovid MEDLINE and CINAHL focused on exploring the effectiveness of 
outcomes of pharmacologic and nonpharmacologic nursing interventions in reducing acute and chronic pain in adult hospitalized patients. Four systematic reviews and 21 original research studies published from 2003-2014 were critiqued for level of evidence using the Centre for Evidence-Based Medicine guideline ${ }^{14}$ and provided the basis for the intervention in this research study.

The literature synthesis is briefly described beginning with the highest level of evidence (systematic reviews). Four systematic reviews supported a benefit in pain outcomes related to patient pain education, ${ }^{15}$ therapy, ${ }^{16}$ and nonpharmacologic therapy. ${ }^{17,18}$ Six randomized controlled trials described beneficial pain management outcomes from patient education ${ }^{19}$ and nonpharmacologic therapy. ${ }^{20-24}$ Two quasi-experimental studies supported a benefit in pain outcomes related to structured pain rounds ${ }^{25}$ and nonpharmacologic therapy. ${ }^{26}$ Thirteen descriptive, comparative, or correlational designs described positive pain care quality outcomes associated with patient pain education, ${ }^{27}$ pain and coping assessment strategies, ${ }^{28-33}$ communication of pain management plans, ${ }^{34}$ pharmacologic therapy, ${ }^{35}$ and nonpharmacologic therapy. ${ }^{36-39}$

Although pharmacologic agents have been the mainstay of pain management, synthesis of this body of knowledge suggests that the evidence is insufficient to support a specific nursing intervention that effectively manages pain. Yet case studies that tested individual nonpharmacologic interventions in the 2010 Pain Care Quality Study reported by Potter et $\mathrm{al}^{40}$ reported a potential benefit for hospitalized adults at single sites. Interventions described in the literature review supporting this study were associated with a potential benefit as adjuncts to pharmacologic therapies that included patient education, clinical pathways, teaching patients coping strategies, and various nonpharmacologic therapies (massage, relaxation, guided imagery, pet therapy, music therapy, prayer, distraction) in improving patients' perceptions of pain management. None of these interventions was found to be harmful or of less benefit than usual care. However, despite the state of knowledge about various adjunctive strategies to individualize pain management in hospitalized adults with acute and chronic pain syndromes, important substantive and theoretical questions exist. These gaps include that little or no knowledge exists regarding the effect of bundling pain care strategies on patients' perceptions of pain care quality.

However, structured quality improvement initiatives and observational cohorts using bundled interventions to improve hospital outcomes in ventilator-associated pneumonia (VAP) ${ }^{41,42}$ and septic shock ${ }^{43,44}$ support improvement in these outcomes when bundle adherence with completing all bundle components reaches and exceeds $80 \%$ over time. Although quality improvement and observational studies are not strong evidence to support the role of bundle adherence in improving quality outcomes in VAP and septic shock, the literature does support a relationship between bundle adherence and quality outcomes. ${ }^{41-43}$ Therefore, it seemed plausible to test the same bundling concept using the $80 \%$ adherence goal in implementing all 6 pain care strategies as one bundle in an intervention study. This research study addressed the knowledge gap and sought to test an important substantive clinical question: determining the effect of a 6 -component bundle of pain care strategies, BITE Pain Therapy ${ }^{\mathrm{TM}}$ (Bundling Interventions to Enhance Pain Care Quality), on patients' perception of pain care quality. The purpose of this nurse-driven, interprofessional, patient-centered project was to implement BITE Pain Therapy $^{\mathrm{TM}}$, a standardized bundle of conceptually aligned evidence-based pain care management strategies, to improve patients' perception of pain care quality by actively engaging the patient as a partner rather than a recipient of treatment. Active engagement of the patient as a healthcare team partner using BITE Pain Therapy ${ }^{\mathrm{TM}}$ was facilitated by 6 bundle components that (1) defined and communicated pain care expectations and (2) determined appropriate pain care interventions. This study was particularly important because if the hypothesis that the BITE Pain Therapy ${ }^{\mathrm{TM}}$ intervention improves medical surgical patients' perceptions of pain care quality was supported, nurses could add a bundle of evidence-based, pragmatic, and readily accessible pain care strategies to their armamentarium in the battle against pain in hospitalized patients.

\section{RESEARCH QUESTIONS}

The research questions that guided this scientific inquiry were (1) To what extent does implementation of a unitbased standardized bundle of evidence-based pain care components (BITE Pain Therapy ${ }^{\mathrm{TM}}$ ) improve medical surgical patients' perception of pain care quality over time? and (2) Is there a relationship between BITE Pain Therapy ${ }^{\mathrm{TM}}$ intervention adherence, patients' perception of pain care quality, and pain experience outcomes?

\section{METHODS \\ Design}

A quasi-experimental interrupted time series design was used to evaluate the effect of the BITE Pain Therapy ${ }^{\text {TM }}$ intervention on patients' perceptions of pain care quality and 24hour pain experience outcomes. Unit-level pain quality data were collected monthly for 4 months before implementation and 30 months after. Unit intervention adherence data were collected weekly and averaged monthly. The study was performed according to good clinical practice principles and was approved by the participating facility's institutional review board (IRB).

\section{Setting}

The study was conducted on 3 medical surgical units in a 550-bed quaternary acute care academic facility in metropolitan New Orleans, LA, with Magnet Recognition $®$ (American Nurses Credentialing Center, Silver Spring, MD). Patients on each of the 3 adult units are primarily specialty populations: gastrointestinal disorders (38 beds), orthopedics (42 beds), and transplant (34 beds). However, all 3 units are similar in that $>60 \%$ of the patients are admitted for major surgical procedures.

\section{Sample and Sampling Plan}

A convenience sample of all patients meeting inclusion criteria on the 3 participating medical surgical units was recruited to participate in the study. The sampling plan involved recruiting patients on a predetermined day of each month during the 4-month preintervention and 30-month postintervention periods. All patients on each unit were screened by study staff for eligibility using the electronic 


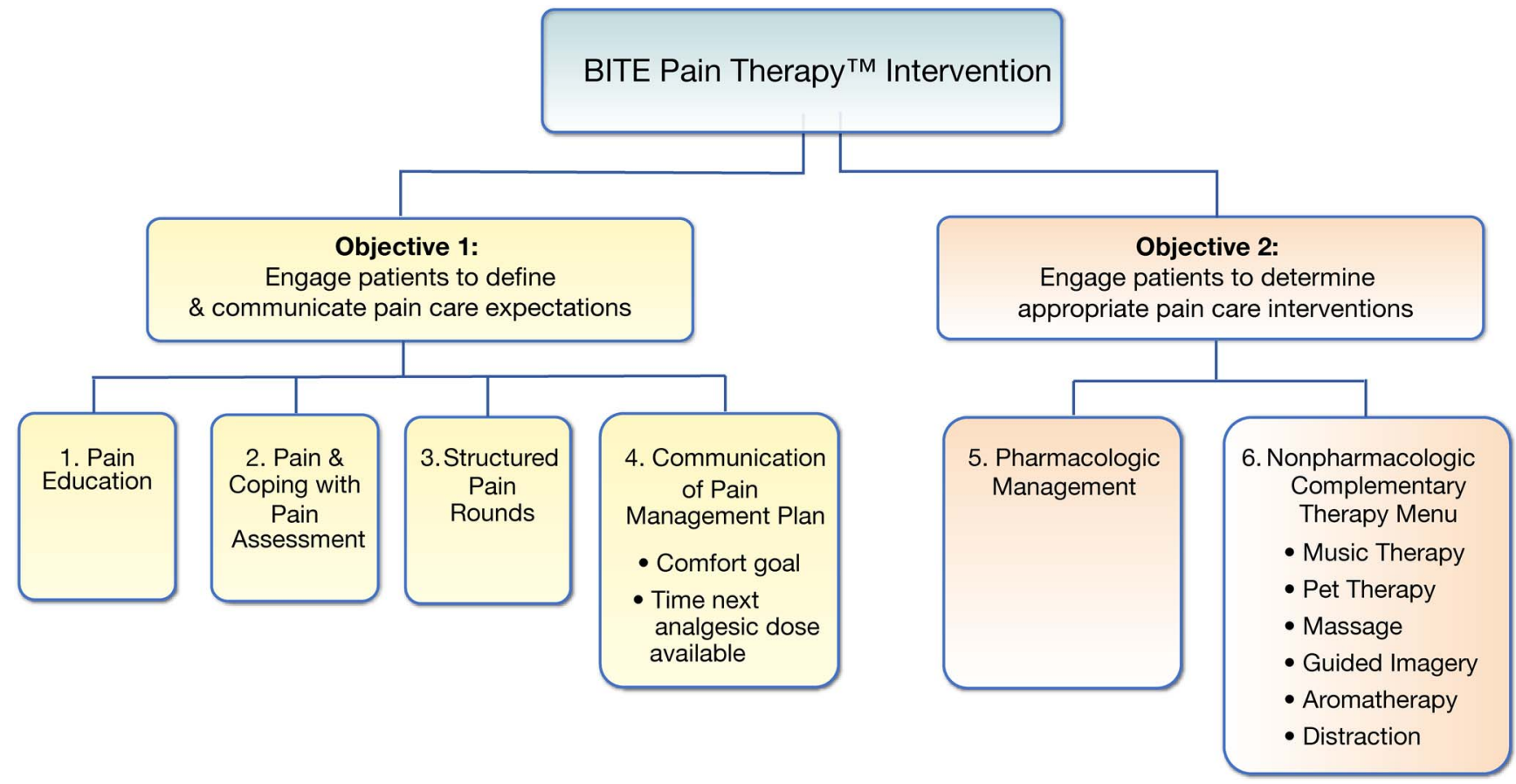

Figure 1. BITE Pain Therapy ${ }^{\mathrm{TM}}$ (Bundling Interventions to Enhance Pain Care Quality) objectives and components.

health record and daily unit census reports. All eligible patients were invited to voluntarily consent to participate if the inclusion criteria were met: $\geq 18$ years old, on that unit at least 24 hours, complaint of pain in the last 24 hours with an active order for pharmacologic analgesic, and able to speak and read English. Patients were excluded if they had a history of cognitive dysfunction, an acute mental status change, or a medical condition that precluded their ability to participate in a 15-minute interview for collecting data.

\section{Intervention}

The BITE Pain Therapy ${ }^{\mathrm{TM}}$ intervention was implemented on November 1, 2014 as a new best practice for the management of acute and chronic pain for all patients hospitalized on the 3 participating units. BITE Pain Therapy ${ }^{\mathrm{TM}}$, a 6-component bundled intervention, was developed by the investigators based on the synthesis of evidence previously described in the literature review. The 6 bundle components (Figure 1) included (1) patient education regarding pain and pain management (pain brochure and individualized instruction); (2) pain and coping with pain assessments using the 0-10 numeric rating scale with faces; (3) structured pain rounds every hour during the day and every 2 hours at night if the patient was awake; (4) communication of the pain management plan (comfort goal and time next analgesic dose available) written on the patient's wall-mounted whiteboard; (5) pharmacologic management; and (6) the offer of menudriven adjunctive nonpharmacologic therapies.

Although these bundle components are congruent with the standard of care, the development of a coping with pain assessment instrument (Figure 2) and a menu for patients to select nonpharmacologic therapy options were innovative additions to the intervention. Patients were provided a menu, Take the BITE Out of Pain, on admission (Figure 3).
The expectation was that all patients with a complaint of pain would be offered the entire 6-component BITE Pain Therapy ${ }^{\mathrm{TM}}$ bundled intervention each shift as the new standard of care. Each participating unit was supplied with two supply carts called comfort carts that included nonpharmacologic therapies (ie, essential oils, distraction materials, massagers). Comfort carts were audited, and the supplies were replaced each week or more often if nurses reported a need.

All participating unit-based provider stakeholders (nurses, advanced practice nurses, physicians, physician assistants, clinical pharmacists, social workers, physical and occupational therapists, pastoral care providers) received education regarding the BITE Pain Therapy ${ }^{\mathrm{TM}}$ intervention, including information about knowledge and attitudes about pain management and implementation of the pain care bundle. Nurses' competencies in completing all bundle components were validated using role modeling and case study vignette simulations. The institution's Pain Task Force accepted

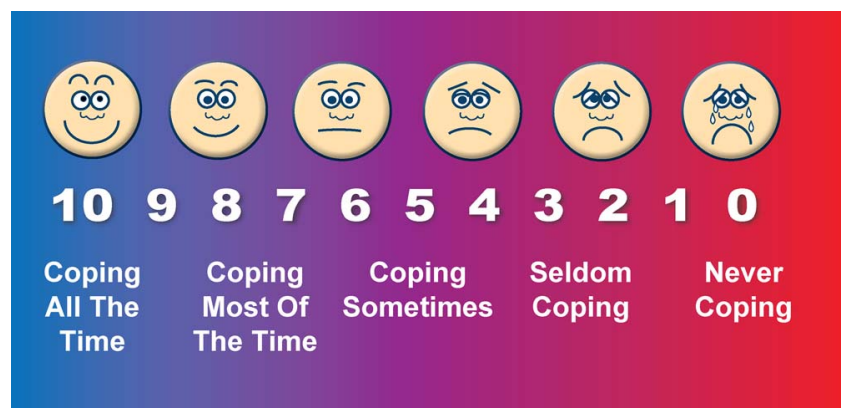

Figure 2. Ability to cope with pain rating scale. 


\section{Take the BITE Out of Pain}

\section{Nonpharmacologic Therapy Menu}

\begin{tabular}{|c|c|c|c|}
\hline $\begin{array}{l}\text { Music Therapy } \\
\text { - TV Channel } 20 \\
\text { - Listen to your music }\end{array}$ & $\begin{array}{l}\text { Relaxation } 1 \\
\text { - Deep breathing } \\
\text { - Stretching } \\
\text { - Progressive muscle } \\
\text { relaxation } \\
\text { - Prayer } \\
\text { - Meditation }\end{array}$ & $\begin{array}{l}\text { Guided Imagery }{ }^{1} \\
\text { - Meditate on images } \\
\text { on music TV } \\
\text { Channel } 20 \\
\text { - Create own images } \\
\text { }{ }^{1} \text { Ask your nurse for } \\
\text { instructions }\end{array}$ & $\begin{array}{l}\text { Distraction } \\
\text { - Read } \\
\text { - Electronic games } \\
\text { - Crossword puzzles, } \\
\text { word searches } \\
\text { - Board games } \\
\text { - Watch TV }\end{array}$ \\
\hline
\end{tabular}

\section{Ask your nurse about arranging the following therapies}

\section{Music Therapy ${ }^{2}$ Massage Therapy \\ - Live music in your room \\ - Battery operated massage units \\ Aromatherapy \\ - Essential oils to smell}

\section{Positioning}

- Repositioning

- Elevation of extremity
Distraction

Resources

- Crossword puzzles, word searches

- Checkers/Chess

- Books

- Have someone read to you ${ }^{2}$

${ }^{2}$ Call Volunteer Services to schedule NOTE: Based on availability

Figure 3. Nonpharmacologic therapy menu.

responsibility for facilitating physician and advanced practice clinician (nurse practitioners, physician assistants) pain management education involving the BITE Pain Therapy ${ }^{\mathrm{TM}}$ bundle. Ongoing education was facilitated using online intranet-based educational modules, skills fairs, and unitbased huddles.

\section{Measurement and Instruments}

Pain Care Quality (PainCQ $\left.{ }^{\odot}\right)$. Patients' perception of pain care quality, the primary endpoint, was measured using 2 different surveys: Pain Care Quality-Interdisciplinary (PainCQ$\left.I^{\odot}\right)$ and Pain Care Quality-Nursing (PainCQ-N ${ }^{\odot}$ ) surveys. ${ }^{45}$ These surveys collect information about the patient's pain care experience in the context of a specific encounter and provider interactions during hospitalization. The surveys focus on a comprehensive assessment of pain management that impacts the patient, family, and friends, including nonpharmacologic therapies and fear of addiction. Patients' perception of pain care quality was measured using the PainCQ ${ }^{\odot}$ surveys monthly during 2 periods: preintervention
(4 months) and postintervention (30 months). In addition, demographic information and 5 selected items from the Brief Pain Inventory ${ }^{46}$ about participants' pain experience during the previous 24 hours were solicited at the same time the PainCQ ${ }^{\odot}$ surveys were administered. While demographic items included self-reported type of pain (acute, chronic, or both types), the 5 items eliciting information about patients' pain experience during the previous 24 hours focused on pain outcomes (average pain level, time in severe pain, frequency of pain medication administration, percent pain relief from medications, ability to cope with pain). Preintervention participants completed the same PainCQ ${ }^{\odot}$ surveys as postintervention participants with one exception. Demographic items in the preintervention survey did not request participants to self-identify the type of pain they were currently experiencing.

Following informed consent, trained data collectors used pen and paper surveys to collect information via structured interview. Permission to use and revise the Pain Care Quality surveys was granted by the developer. The original 20 -item 
Table 1. Confirmatory Factor Analysis for PainCQ ${ }^{\odot}$ Survey Data

\begin{tabular}{|c|c|c|c|}
\hline Test Statistic & Criteria for Good Model Fit & PainCQ-I ${ }^{\odot}(n=846)$ & PainCQ- $N^{\odot}(n=846)$ \\
\hline Number of items & & 6 & 15 \\
\hline Chi-square (df) & & $21.49(8)$ & $372.79(83)$ \\
\hline$P$ value for chi-square & $<0.05$ & 0.006 & $<0.001$ \\
\hline Chi-square ratio & $\chi^{2} / \mathrm{df}(<3)$ & 2.69 & 4.48 \\
\hline Comparative fit index & $\geq 0.95$ & 0.99 & 0.95 \\
\hline Goodness-of-fit index & $\geq 0.95$ & 0.99 & 0.94 \\
\hline Standardized root mean square residual & $\leq 0.08$ & 0.023 & 0.050 \\
\hline Root mean square error of approximation & $\leq 0.08$ & 0.045 & 0.065 \\
\hline
\end{tabular}

Note: Missing data replaced with subscale mean to facilitate complete dataset for confirmatory factor analysis. df, degrees of freedom; PainCQ-1 ${ }^{\odot}$, Pain Care Quality-Interdisciplinary; PainCQ- $\mathrm{N}^{\odot}$, Pain Care Quality-Nursing.

survey includes pain care quality items specific to interdisciplinary care (6 items) and nursing pain care (14 items). ${ }^{45,47}$ Altogether, these 20 items specifically measure patients' perception of pain care quality, and they make up the PainCQ$1^{\odot}$ and the PainCQ-N ${ }^{\circledR}$ surveys. The 6 items included on the PainCQ- $I^{\odot}$ survey are categorized under 2 subscales: Partnership with the Health Care Team (3 items) and Comprehensive Interdisciplinary Pain Care ( 3 items). The 14 items on the PainCQ- $\mathrm{N}^{\odot}$ survey are categorized under 3 subscales: Being Treated Right (7 items), Comprehensive Nursing Pain Care (4 items), and Efficacy of Pain Management (3 items). ${ }^{47}$ Both the PainCQ- ${ }^{\odot}$ and PainCQ-N ${ }^{\odot}$ surveys use a 6 -point Likert rating scale ( $1=$ strongly disagree to $6=$ strongly agree) to elicit information about pain care quality related to interdisciplinary care since admission to the hospital (ie, PainCQ$1^{\circ}$ ) and nursing care during the previous 12-hour shift (ie, PainCQ- $\mathrm{N}^{\odot}$ ). Higher scores indicate better pain care quality.

Because the BITE Pain intervention included an option of nonpharmacologic therapies thought to improve patients' ability to cope with pain, ${ }^{17,18,48,49}$ it was important to assess the patients' baseline coping ability and the impact of nursing care as confounding variables. Therefore, 2 additional questions were developed in collaboration with the instrument developer. One of the items previously mentioned in the 5 -item section that assessed the patient's pain experience during the last 24 hours-Please rate how effectively you are coping with pain on the average during past 24 hours - uses a numeric rating scale with faces $(10=$ coping all the time to $0=$ never coping). The second question-The nurse did a good job helping me to cope with my pain - was added to the PainCQ- $\mathrm{N}^{\odot}$ Being Treated Right subscale items, increasing this subscale to 8 items. Information from 34 survey items (8 demographic, 5 pain experience, 20 PainCQ $^{\odot}$, plus 1 new coping question) were collected from participants.

The 20 items making up the original PainCQ- ${ }^{\odot}$ and PainCQ-N ${ }^{\odot}$ surveys ${ }^{47}$ have psychometric estimates to support reliability and validity in measuring patients' perceptions about pain care quality. All 5 subscales have previously reported satisfactory internal consistency reliability and construct validity via confirmatory factor analysis (CFA). ${ }^{47}$ Internal consistency reliability for each subscale of the PainCQ$I^{\odot}$ (6 items) and revised PainCQ-N ${ }^{\odot}$ (15 items) surveys used in this study were satisfactory. Cronbach's $\alpha$ for the individual subscales was 0.69 (Partnership with the Health Care
Team), 0.71 (Comprehensive Interdisciplinary Pain Care), 0.87 (Being Treated Right), 0.71 (Comprehensive Nursing Pain Care), and 0.88 (Efficacy of Pain Management). CFA supported the validity of the construct in this study, and the data fit the model for both the PainCQ- ${ }^{\odot}$ and revised PainCQ-N ${ }^{\odot}$ surveys (Table 1 ).

BITE Pain Therapy ${ }^{\mathrm{TM}}$ Intervention Fidelity. Measuring intervention adherence is critical to determining whether perceptions of pain care quality are attributable to the intervention or to some other confounding variable. The researchers developed an audit tool to measure patients' perception of nurses' adherence with each of the 6 bundle components using a dichotomous (yes/no) response. Patients were selected for auditing based on the same eligibility criteria used in conducting the Pain $\mathrm{CQ}^{\odot}$ surveys. Using the same audit instrument, 2 strategies were used to assess the impact of the intervention on patients' perception of pain care quality and pain outcomes. First, unit-based adherence of the intervention was captured weekly but at a different time than pain care quality and pain outcome data collection. Second, individual participant intervention adherence was collected monthly at the same time as pain care quality and pain outcome data collection, providing paired data for some participants in the postintervention group.

Unit-Based Intervention Adherence Audits. Unit-based audits were conducted by research assistants each week via patient interview and observation. Consented patients were interviewed regarding their recollection that the bundle options were offered during the prior 24 hours and by observation of written communication of the pain management plan on whiteboards in the hospital room. Bundle adherence audits were scored to determine the percentage of adherence for each bundle component and for all 6 bundle components. This information was communicated back to nurses on each participating unit weekly to foster improved adherence with all 6 bundle components over time. In addition, nurses were encouraged to anonymously complete a pocket card weekly to communicate processes that worked well or presented obstacles to bundle adherence (Figure 4).

Individual Participant Intervention Adherence Audits. To investigate the effects of the bundle components on improving the perception of pain care quality, defining and capturing participants' exposure to the intervention were necessary. In June 2015, the protocol was amended and approved by 


\begin{tabular}{|c|c|}
\hline $\begin{array}{r}\text { BIT } \\
\text { What's Workin }\end{array}$ & $\begin{array}{l}\text { Pain Therapy } \\
\text { for Nurses \& What's Not }\end{array}$ \\
\hline $\begin{array}{l}\text { Instructions: Please eva } \\
\text { Pain Interventions is wo } \\
\text { any comments that will } \\
\text { back of this card for ado }\end{array}$ & $\begin{array}{l}\text { luate whether or not each of the BITE } \\
\text { rking (you can or cannot do it). Include } \\
\text { help us to improve this project. Use the } \\
\text { ditional comments. }\end{array}$ \\
\hline Date:__ Shift: & $\begin{array}{llll}\text { Unit (circle 1): } & 1 & 2 & 3\end{array}$ \\
\hline $\begin{array}{l}\text { BITE Pain } \\
\text { Intervention }\end{array}$ & $\begin{array}{l}\text { Comments } \\
\text { (especially what is } \\
\text { not working) }\end{array}$ \\
\hline $\begin{array}{l}\text { Pain } \& \text { coping } \\
\text { assessment at same } \\
\text { time }\end{array}$ & YES \\
\hline $\begin{array}{l}\text { Structured pain rounds } \\
\text { per guideline }\end{array}$ & YES $\square$ NO \\
\hline $\begin{array}{l}\text { Whiteboard to } \\
\text { communicate pain } \\
\text { therapy }\end{array}$ & YES \\
\hline $\begin{array}{l}\text { "Taking the BITE Out of } \\
\text { Pain" menu (daily } \\
\text { review) }\end{array}$ & YES \\
\hline $\begin{array}{l}\text { Access to } \\
\text { pharmacologic agents } \\
\text { for pain when you } \\
\text { needed them }\end{array}$ & YES \\
\hline $\begin{array}{l}\text { Able to facilitate } \\
\text { complementary } \\
\text { therapy options } \\
\text { selected by patient }\end{array}$ & $\begin{array}{l}\text { YES } \square \text { NO } \square \\
\text { No requests } \square\end{array}$ \\
\hline $\begin{array}{l}\text { Scheduled volunteer } \\
\text { services without } \\
\text { problem }\end{array}$ & $\begin{array}{l}\text { YES } \square \text { NO } \square \\
\text { No requests } \square\end{array}$ \\
\hline
\end{tabular}

Figure 4. Nurses' pocket card to assess what was working and not working.

the IRB. In addition to the monthly intervention adherence audits, this amendment provided a mechanism to capture individual participant intervention adherence data on some of the postintervention group at the same time as pain care quality and pain outcome data were collected.

Participant data from the entire preintervention $(n=141)$ period and from individual audits $(n=453)$ from some in the postintervention period were categorized into groups according to their exposure to the intervention. Three groups were defined: Group 1 Preintervention (no bundle), Group 2 Postintervention (offered 0-5 bundle components), and Group 3 Postintervention (offered all 6 bundle components). The team's rationale was (1) no one in Group 1 was exposed to the bundle; 2 of the components were not available (ability to cope with pain assessment and nonpharmacologic menu); (2) participants in Group 2 who reported receiving 0-5 components were exposed to at least 1 component (pharmacologic analgesia was an inclusion criterion) during their hospitalization even if they were not consciously aware; and (3) the number of participants in Group 3 who reported receiving all 6 bundle components at the time PainCQ ${ }^{\odot}$ survey data were collected supports intervention adherence. Therefore, the primary analysis of the effect of the bundled intervention focused on comparing the pain care quality scores and pain outcomes of 3 participant groups that had paired data to support whether or not exposure to the intervention occurred.

\section{DATA ANALYSES}

Exploratory data analysis was conducted to examine the distributions of each study variable, primary and secondary endpoints by means \pm standard deviations, and frequencies and percentages. Medians and interquartile ranges were reported when continuous data were not normally distributed. All analyses were completed using SAS/STAT software, v.9.4 of the SAS System for Windows. All tests were performed with significance level $\alpha=0.05$.

Pain experience outcome data were dichotomized into 2 groups of responses for average pain (low $=0-4$ rating vs high $=5-10$ rating), time in severe pain $(0 \%-25 \%$ vs $26 \%$ $100 \%)$, amount of relief from pharmacologic analgesia $(0 \%-$ $75 \%$ vs $80 \%-100 \%$ ), and ability to cope with pain (0-6 rating vs 7-10 rating). Little variability was seen among patients' responses, and dichotomizing allowed us to see the separation between participant responses more clearly. In addition, the dichotomized groups were aligned with existing clinical practice goals for quality improvement of pain care outcomes at this organization.

Data were analyzed using 2 approaches: (1) testing the entire participant sample's demographics, pain care quality and pain experience outcome data, and unit-based monthly mean intervention adherence measures for the 6-component bundle and (2) testing the subsample of participants with individual-level intervention adherence data paired with pain care quality and pain experience outcome data.

\section{Entire Participant Sample Analysis $(n=846)$}

Demographic characteristics for the entire sample are reported as means and standard deviations for continuous measures and as frequencies and percentages for categorical measures. Chi-square tests were used for comparisons of the dichotomized 24-hour pain experience outcomes regarding time in severe pain, relief from pain, and ability to cope between participants reporting low vs high average pain. Additionally, all 3 dichotomized outcomes were compared via chi-square tests between groups defined by the dichotomized type of reported pain. A multinomial ordinal regression model incorporating an interrupted time series design was used to test for changes from preintervention to postintervention in means and time trends in $P$ ainCQ ${ }^{\odot}$ scores across the sample and within each unit. Differences in changes from preintervention to postintervention in means and time trends in PainCQ ${ }^{\odot}$ scores between units were also tested.

\section{Subsample Analysis $(n=594)$}

A subsample analysis was completed using the preintervention participant data $(n=141)$ and data collected on postintervention participants $(n=453)$ with individual paired data for intervention adherence for the bundle components, PainCQ ${ }^{\odot}$ and pain experience outcomes. As previously described, participants were categorized into 3 groups (Group 1 Preintervention, Group 2 Postintervention [receiving 0-5 bundle components], and Group 3 Postintervention [receiving all 6 bundle components]) for comparison. Sample size was determined from a power analysis of 
PainCQ ${ }^{\odot}$ scores. To achieve $80 \%$ power to detect differences in $\mathrm{Pain} C \mathrm{Q}^{\odot}$ scores between the 3 adherence groups, a total sample size of $n=231$ is sufficient. The power and sample size calculations are based on the expectation of observed means equal to $4.0,4.5$, and 5.0 for the preintervention, postintervention with partial intervention adherence, and postintervention with full adherence groups, respectively. A standard deviation of 1.0 was assumed for all participant groups, and the calculations were adjusted to account for multiple comparisons. Because of the non-normality of the actual observed PainCQ ${ }^{\odot}$ scores in this study, the subsequently described group comparisons utilized nonparametric methods. Although less powerful than analogous parametric tests, we concluded that the amassed sample size of $n=594$ was sufficient to maintain adequate power.

Using one-way ANOVA for continuous measures and chisquare tests for categorical measures, demographics and type of pain were compared. To test for group differences in the study outcomes, Kruskal-Wallis tests were used for distributions of $P$ ainCQ ${ }^{\odot}$ scores and subscale scores, chisquare tests were used for associations with 24-hour pain care experience responses, and odds ratios (ORs) from a multinomial ordinal regression model were used for odds of higher $P$ ain $\mathrm{CQ}^{\odot}$ scores. Finally, intervention adherence data for the 2 postintervention groups $(n=453)$ were tested using chi-square tests for associations between exposure to individual bundle components and 24-hour pain experience outcomes.

\section{RESULTS}

\section{Participant Characteristics}

A total of 1,290 patients met eligibility criteria over the course of the 34-month study period, with 856 (66.4\%) consenting (Figure 5). Ten of 856 participants withdrew without completing the survey because of a change in their medical condition (ie, pain, fatigue, nausea). Data from 846 participants were included in analyses. Participants' self-reported demographic characteristics for the sample $(n=846)$ included a mean age of 54.4 years $(S D=14.4)$ and $50.9 \%$ male. Significantly more participants were white $(66.1 \%)$, not Hispanic or Latino (94.4\%), married/partnered (51.8\%), and completed at least some college (54.3\%) (Table 2).

Of the 846 participants, 141 (16.7\%) completed the PainCQ ${ }^{\odot}$ surveys during the preintervention study period, July through October 2014. As previously stated, the 3 self-reported pain types (acute, chronic, or both) were only collected from postintervention participants, representing $704 / 846(83.2 \%)$ of the sample, with the majority $(413 / 704$ [58.7\%]) reporting acute pain compared to $125 / 704(17.8 \%)$ reporting chronic pain and 166/704 (23.6\%) with both acute and chronic pain (Table 2).

A group comparison of all participants $(n=846)$ based on reported 24-hour pain experience was completed. When 24hour pain experience outcomes were dichotomized by low vs high average pain ratings, participants who reported a lower average daily pain score reported significantly less time in severe pain, greater pain relief from pharmacologic analgesia, and higher ability to cope with pain (Table 3). However, when 24-hour pain experience data were analyzed from the 704 postintervention participants from whom pain type was collected (Table 4), differing patterns of associations were observed between participants reporting acute

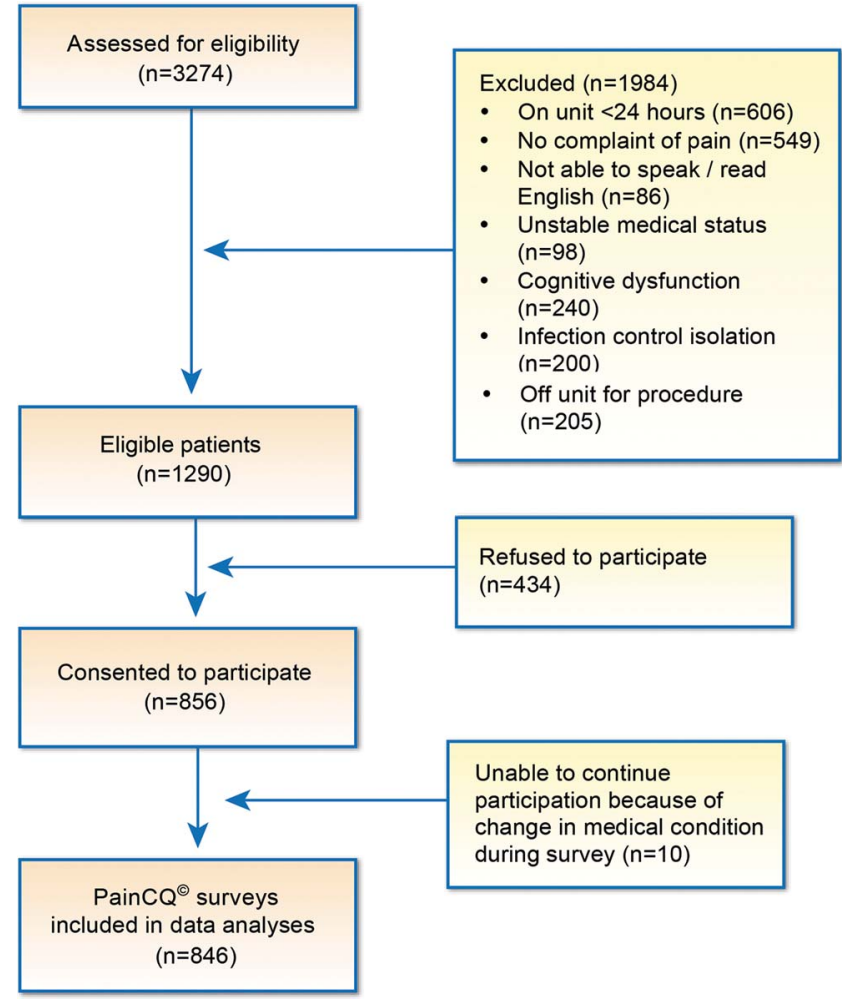

Figure 5. Participant flow chart.

pain compared to participants who reported chronic or acute and chronic pain. Participants reporting acute pain alone had more reports of low average pain scores $(22.3 \%)$, less time in severe pain $(65.4 \%)$, and more relief from pharmacologic analgesia (56.7\%) than those with chronic or both acute and chronic pain. No significant differences in ability to cope with pain based on type of pain were found.

\section{Pain Care Quality and Unit-Based Intervention Adherence}

Incorporating the interrupted time series design, an ordinal regression model was used to answer the research question, Does implementation of a unit-based standardized bundle of evidence-based pain care interventions (BITE Pain Therapy ${ }^{\mathrm{TM}}$ ) improve medical surgical patients' perception of pain care quality over time? Figure 6 illustrates that no significant changes occurred in trends of PainCQ- $I^{\odot}(\mathrm{F}[1,836]<0.005 ; P=0.991)$ or PainCQ$\mathrm{N}^{\odot} \quad(\mathrm{F}[1,836]=0.08 ; P=0.776)$ scores over time or in mean PainCQ- $I^{\odot}(\mathrm{F}[1,836]=0.07 ; P=0.792)$ or PainCQ-N ${ }^{\odot}$ $(F[1,836]=0.01 ; P=0.912)$ scores following implementation of the intervention.

\section{Three-Group Participant Findings}

Because the BITE Pain Therapy ${ }^{\mathrm{TM}}$ unit-based intervention adherence for the 6-component bundle failed to meet the monthly average goal of $80 \%$, we were unable to test the hypotheses that bundle adherence had an effect on patients' perception of pain care quality or pain experience outcomes. Faced with a mean unit-based adherence for the 6-component bundle that did not exceed zero percent during the first 7 months of the postintervention period, the protocol 
Table 2. Participant Characteristics

\begin{tabular}{lc}
\hline \multicolumn{1}{c}{ Characteristic } & All Participants $\mathbf{n = 8 4 6}$ \\
\hline Mean age, years \pm SD & $54.4 \pm 14.4$ \\
Sex & \\
Female & $415(49.1)$ \\
Male & $430(50.9)$ \\
Race & \\
Black or African American & $248(29.3)$ \\
White & $559(66.1)$ \\
Other & $39(4.6)$ \\
Ethnic background & \\
Hispanic, Latino, or Spanish origin & $47(5.6)$ \\
Not Hispanic or Latino & $798(94.4)$ \\
Marital status & $196(23.2)$ \\
Single & $127(15.0)$ \\
Separated or divorced & $85(10.0)$ \\
Widow or widower & $438(51.8)$ \\
Married or partnered & \\
Education & \\
Technical school graduate and below & $386(45.7)$ \\
Some college and above & $459(54.3)$ \\
Pain & \\
Acute & \\
Acute and chronic & \\
\hline
\end{tabular}

apain type was collected only on postintervention participants $(n=704)$. Note: Data are reported as $\mathrm{n}(\%)$ unless otherwise indicated.

amendment afforded the opportunity to collect paired pain care quality, pain experience outcome, and bundle component adherence data beginning in the eighth month of the postintervention period. Intervention adherence data were collected on $453 / 705(64.3 \%)$ postintervention participants who completed PainCQ ${ }^{\odot}$ surveys. During the 30 -month intervention period, participants $(n=453)$ reported receiving a mean of 3.9 BITE Pain Therapy ${ }^{\mathrm{TM}}$ bundle components (median 4.0). However, only 65/453 (14.3\%) reported receiving all 6 bundle components (Figure 7). Audit data of each bundle component from the 453 participants revealed that $81.0 \%$ reported receiving pain education, $55.8 \%$ received both pain and coping with pain assessments, $83.8 \%$ experienced structured pain rounds, $38.8 \%$ had whiteboard communication of their comfort goal and next analgesic dose available, $96.0 \%$ were aware they were receiving pharmacologic analgesia, and $41.0 \%$ were offered the complementary therapy menu. The 2 bundle components that negatively impacted intervention fidelity were failure to update the whiteboard communication of the pain management plan and offering the complementary therapy menu.

Table 5 describes the demographic characteristics of the 3 participant groups using the sample of 594: Group 1 Preintervention (no bundle), Group 2 Postintervention (offered 0-5 bundle components), and Group 3 Postintervention (offered all 6 bundle components). No differences $(P>0.05)$ were

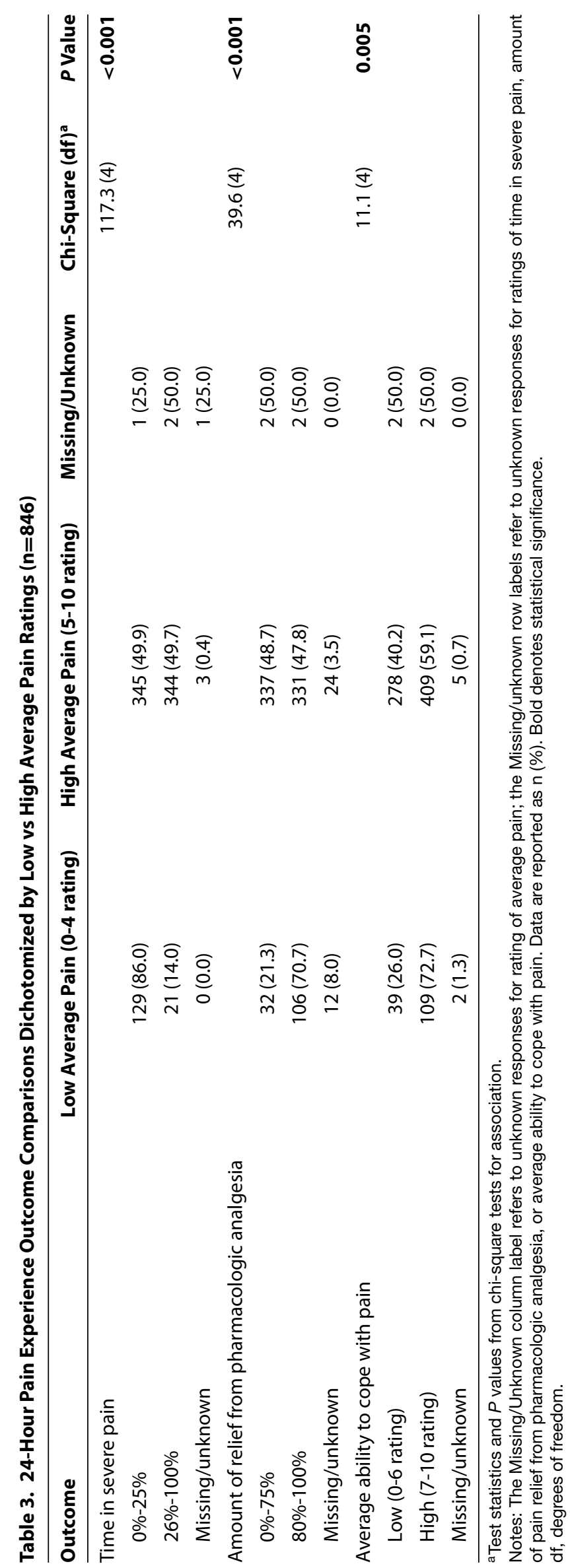

Ochsner Journal 
Rice, $K L$

Table 4. 24-Hour Pain Experience Outcome Comparison by Type of Pain $(n=704)$

\begin{tabular}{|c|c|c|c|c|c|}
\hline Outcome & Acute Pain & Chronic Pain & Acute and Chronic Pain & Chi-Square (df) ${ }^{a}$ & P Value \\
\hline Average pain & & & & $18.3(4)$ & 0.001 \\
\hline Low (0-4 rating) & $92(22.3)$ & $13(10.4)$ & $16(9.6)$ & & \\
\hline High (5-10 rating) & $319(77.2)$ & $111(88.8)$ & $149(89.8)$ & & \\
\hline Missing/unknown & $2(0.5)$ & $1(0.8)$ & $1(0.6)$ & & \\
\hline Time in severe pain & & & & $38.3(4)$ & $<0.001$ \\
\hline $0 \%-25 \%$ & $270(65.4)$ & $55(44.0)$ & $69(41.6)$ & & \\
\hline $26 \%-100 \%$ & $140(33.9)$ & $69(55.2)$ & $97(58.4)$ & & \\
\hline Missing/unknown & $3(0.7)$ & $1(0.8)$ & $0(0.0)$ & & \\
\hline Amount of relief from pharmacologic analgesia & & & & $14.2(4)$ & 0.007 \\
\hline $0 \%-75 \%$ & $165(40.0)$ & $64(51.2)$ & $87(52.4)$ & & \\
\hline $80 \%-100 \%$ & $234(56.7)$ & $55(44.0)$ & $69(41.6)$ & & \\
\hline Missing/unknown & $14(3.4)$ & $6(4.8)$ & $10(6.0)$ & & \\
\hline Average ability to cope with pain & & & & $5.2(4)$ & 0.267 \\
\hline Low (0-6 rating) & $140(33.9)$ & $49(39.2)$ & $69(41.6)$ & & \\
\hline High (7-10 rating) & $270(65.4)$ & $75(60.0)$ & $94(56.6)$ & & \\
\hline Missing/unknown & $3(0.7)$ & $1(0.8)$ & $3(1.8)$ & & \\
\hline
\end{tabular}

${ }^{a}$ Test statistics and $P$ values from chi-square tests for association. Notes: Data are reported as $\mathrm{n}(\%)$. Bold denotes statistical significance. $\mathrm{df}$, degrees of freedom.

seen in age, sex, race, ethnicity, marital status, or highest level of education among the 3 groups. In addition, we found no difference in the distribution of pain types between the 2 postintervention groups.

This 3-group analysis of the preintervention participants and 2 postintervention participant groups identified significant $(P<0.05)$ differences between groups for total PainCQ$I^{\odot}$ and $\mathrm{PainCQ}-\mathrm{N}^{\odot}$ scores, as well as all subscale scores (Table 6). Participants in Group 3 Postintervention who were offered all 6 bundle components had a higher perception of pain care quality compared to either the Group 1 Preintervention participants or the Group 2 Postintervention participants.

Regression analysis of ordered multinomial PainCQ- ${ }^{\odot}$ and PainCQ- $\mathrm{N}^{\odot}$ scores by group suggests that the odds of higher pain care quality scores were not statistically different between Group 2 and Group 1 (Table 7). However, Group 3 had significantly higher odds of higher scores for both the PainCQ-I ${ }^{\odot}(\mathrm{OR}>2.5)$ and PainCQ-N ${ }^{\odot}(\mathrm{OR}>3.8)$ surveys vs both Group 1 and Group 2 (Table 7).

We found no significant differences $(P>0.05)$ between Group 1 Preintervention participants and participants in the 2 postintervention participant groups for 24-hour pain outcomes (Table 8). Although the majority of participants in all 3 groups reported a high average daily pain score (score $>5$ ), the majority also reported less time in severe pain $(<26 \%$ of the time) and higher abilities to cope with pain (score $>6)$. In contrast, reports of the percentage of pain relief from pharmacologic analgesia for the 3 groups were variable.

Even though participants who received all 6 bundle components did not demonstrate a significant impact on 24-hour pain experience outcomes, a secondary analysis of each bundle component did identify the following findings. When each bundle component was tested for an association with each of the 24-hour pain experience outcomes, one bundle component significantly improved two of the four 24hour pain outcomes (Table 9). Participants who received the structured Pain Rounds bundle component vs those who did not reported significantly less time in severe pain and a higher ability to cope with pain.

\section{DISCUSSION}

To our knowledge, this study is the first to test the effect of a patient-centered bundled pain management intervention on medical surgical patients' perception of pain care quality and 24-hour pain experience outcomes. Yet because unit-based intervention fidelity failed to meet the goal of $80 \%$ adherence with the BITE Pain Therapy ${ }^{\mathrm{TM}}$ 6-component bundle, we were unable to determine an effect of the unitbased intervention on patients' perception of pain care quality and 24-hour pain experience outcomes comparing the preintervention to postintervention periods as initially proposed. However, the sample size was sufficient to complete a 3-group analysis that allowed us to compare participants' perception of pain care quality and 24-hour pain experience outcomes with confirmed intervention adherence in a subsample of $70.2 \%$ (594/846) of participants. This subsample was representative of the patient populations cared for on all 3 participating units for sex, age, and ethnicity, with no significant differences in the distribution of participant characteristics among the 3 groups.

Our subsample findings support that participants receiving the 6-component bundle comprising the BITE Pain Therapy $^{\mathrm{TM}}$ intervention reported significantly higher levels of pain care quality delivered by both nurses and interdisciplinary care teams during hospitalization. In contrast, no 


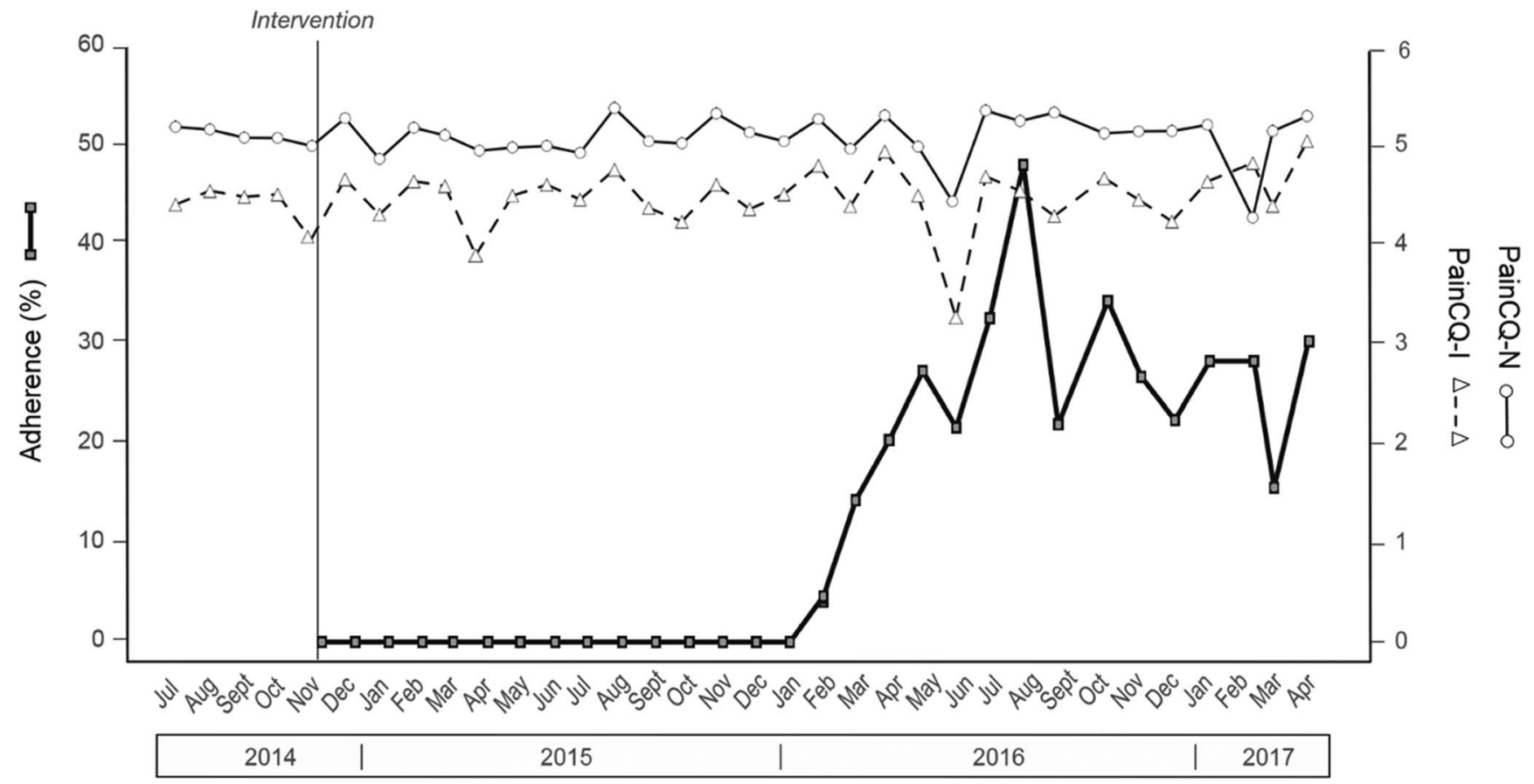

Figure 6. Run chart showing mean monthly unit-based intervention adherence with the 6-component bundle and PainCQ ${ }^{\odot}$ scores for interdisciplinary and nursing surveys during the 34-month study period. PainCQ-I, Pain Care Quality-Interdisciplinary; PainCQ-N, Pain Care Quality-Nursing.

differences in perception of pain care quality were detected between participants in the preintervention group and participants in the postintervention group that did not receive all 6 bundle components. Therefore, this study provides support that using all 6 components comprising BITE Pain Therapy ${ }^{\mathrm{TM}}$ significantly improved the perception of pain care quality in the medical surgical patients who participated in this study.
No relationships were identified between the preintervention and 2 postintervention groups for average pain score, time in severe pain, amount of pain relief from pharmacologic analgesia, or average ability to cope with pain. Overall, the majority of participants in all 3 groups reported an average 24-hour pain rating in the moderate to severe range (5-10 rating), yet reports of less percentage of time in severe pain $(0 \%-25 \%)$ vs more time $(26 \%-100 \%)$ in severe pain were

\section{0}

\section{6}

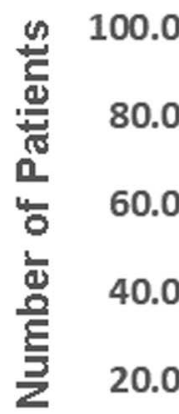

49

$$
0.0
$$

11
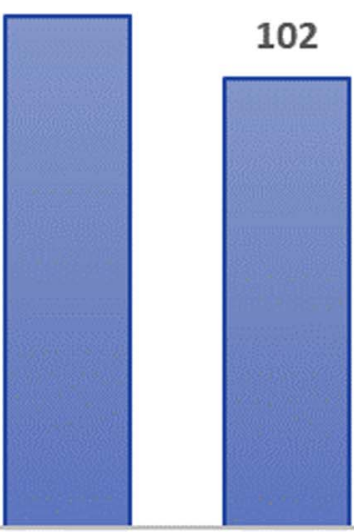

106<smiles>[CH]C1CCC1</smiles>

1

2

3

4

5

6

65

\section{Number of Bundle Components}

Figure 7. BITE Pain Therapy ${ }^{\mathrm{TM}}$ (Bundling Interventions to Enhance Pain Care Quality) bundle adherence for all 6 components $(n=453)$. 
Rice, $K L$

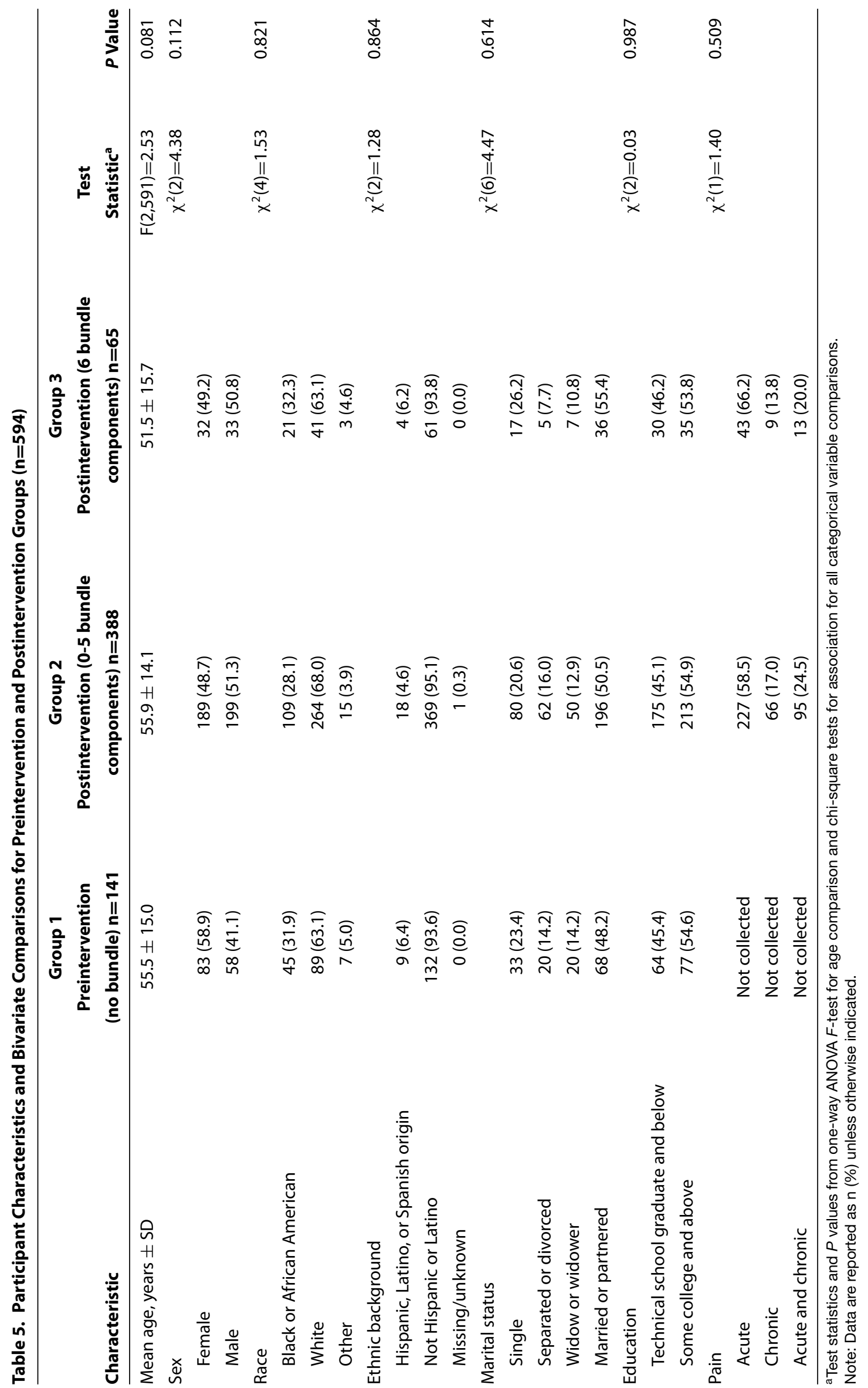




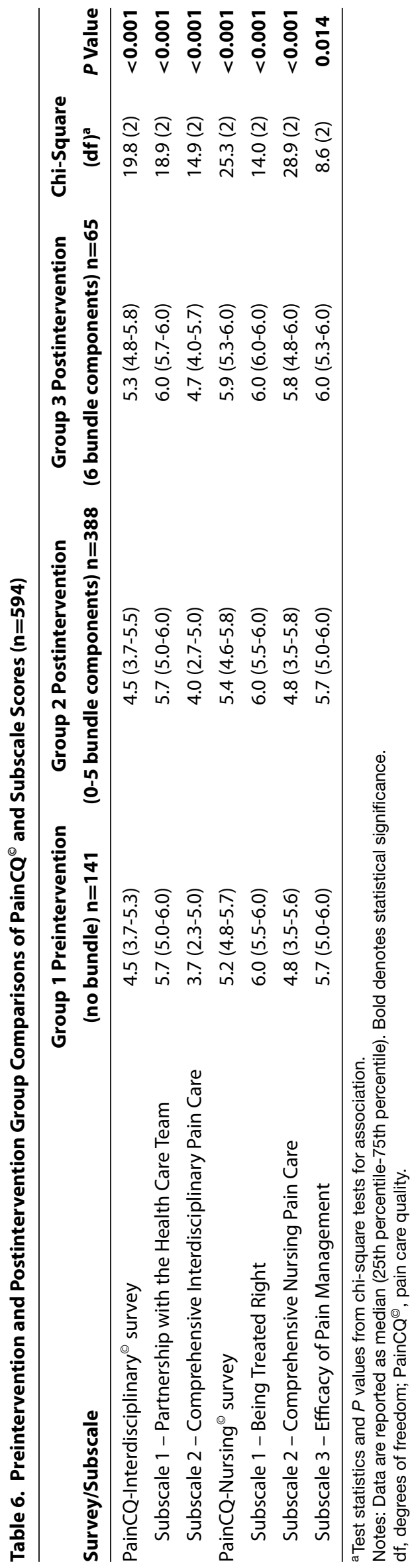

Table 7. Regression Analysis of Ordered Multinomial PainCQ $^{\odot}$ Scores by Preintervention and Postintervention Group $(\mathbf{n}=594)$

\begin{tabular}{|c|c|}
\hline Survey/Comparison Groups & Odds Ratio ${ }^{a}(95 \% \mathrm{CI})$ \\
\hline \multicolumn{2}{|l|}{ PainCQ-Interdisciplinary ${ }^{\odot}$ survey } \\
\hline $\begin{array}{l}\text { Group } 2 \text { Postintervention }{ }^{\mathrm{b}} \text { vs Group } 1 \\
\text { Preintervention }^{\mathrm{c}}\end{array}$ & $1.04(0.73-1.47)$ \\
\hline $\begin{array}{l}\text { Group } 3 \text { Postintervention }{ }^{d} \text { vs Group } 1 \\
\text { Preintervention }^{c}\end{array}$ & $2.61(1.54-4.42)$ \\
\hline $\begin{array}{l}\text { Group } 3 \text { Postintervention }{ }^{d} \text { vs Group } 2 \\
\text { Postintervention }^{b}\end{array}$ & $2.52(1.57-4.03)$ \\
\hline \multicolumn{2}{|l|}{ PainCQ-Nursing ${ }^{\odot}$ survey } \\
\hline $\begin{array}{l}\text { Group } 2 \text { Postintervention }{ }^{b} \text { vs Group } 1 \\
\text { Preintervention }^{c}\end{array}$ & $0.99(0.70-1.42)$ \\
\hline $\begin{array}{l}\text { Group } 3 \text { Postintervention }{ }^{d} \text { vs Group } 1 \\
\text { Preintervention }^{c}\end{array}$ & $3.82(2.06-7.09)$ \\
\hline $\begin{array}{l}\text { Group } 3 \text { Postintervention }{ }^{d} \text { vs Group } 2 \\
\text { Postintervention }^{b}\end{array}$ & $3.84(2.17-6.80)$ \\
\hline $\begin{array}{l}\text { aOdds ratios represent odds of a higher score } \\
{ }^{\mathrm{b}} \text { Group } 2 \text { Postintervention ( } 0-5 \text { bundle compo } \\
{ }^{\circ} \text { Group } 1 \text { Preintervention (no bundle). } \\
\text { dGroup } 3 \text { Postintervention ( } 6 \text { bundle compone } \\
\mathrm{Cl}_{\text {, confidence interval; Pain } \mathrm{CQ}^{\odot} \text {, pain care qu }}\end{array}$ & $\begin{array}{l}\text { on the } \mathrm{PainCQ}^{\odot} \text { scale. } \\
\text { nents). }\end{array}$ \\
\hline
\end{tabular}

almost equally split. The incongruence between the majority of participants' reports of moderate to severe pain and less percentage of time in severe pain may be explained by the dichotomization of these measures. Even though others have reported the validity of categorizing numerical pain ratings into 3 groups (mild, moderate, and severe pain), ${ }^{50,51}$ we chose to categorize pain ratings into 2 groups based on our institution's quality improvement goals related to pain. The accuracy of participant recall could also have biased painrelated outcome measurement and contributed to the incongruence between average 24-hour pain ratings and percentage of time in severe pain. However, other studies support the validity of patient recall related to reporting average pain scores for both 24 -hour ${ }^{52,53}$ and 1-week time periods. ${ }^{54}$

In addition, we found no differences between groups in participants' reports of the amount of relief from pharmacologic analgesia. Fifty-seven percent of the preintervention group reported $\geq 80 \%$ relief from pharmacologic analgesia compared to an almost equal split between $<80 \%$ and $\geq 80 \%$ in the 2 postintervention groups. While the latter finding was not significant, organization-wide strategies to promote adjunctive nonpharmacologic pain management to reduce opioid use were launched at the same time that this research study began. Therefore, pharmacologic analgesia alone would have been the mainstay of pain management during the preintervention period and may have contributed to reports of $\geq 80 \%$ relief from analgesics. Nevertheless, we did not measure opioid use, so we are unable to determine if the differences in opioid administration differed between the preintervention or postintervention groups and contributed to reports of increased pain relief from pharmacologic analgesia in the preintervention group.

The bundled intervention did not have a significant effect on participants' ability to cope with pain. Although the major- 
Rice, $K L$

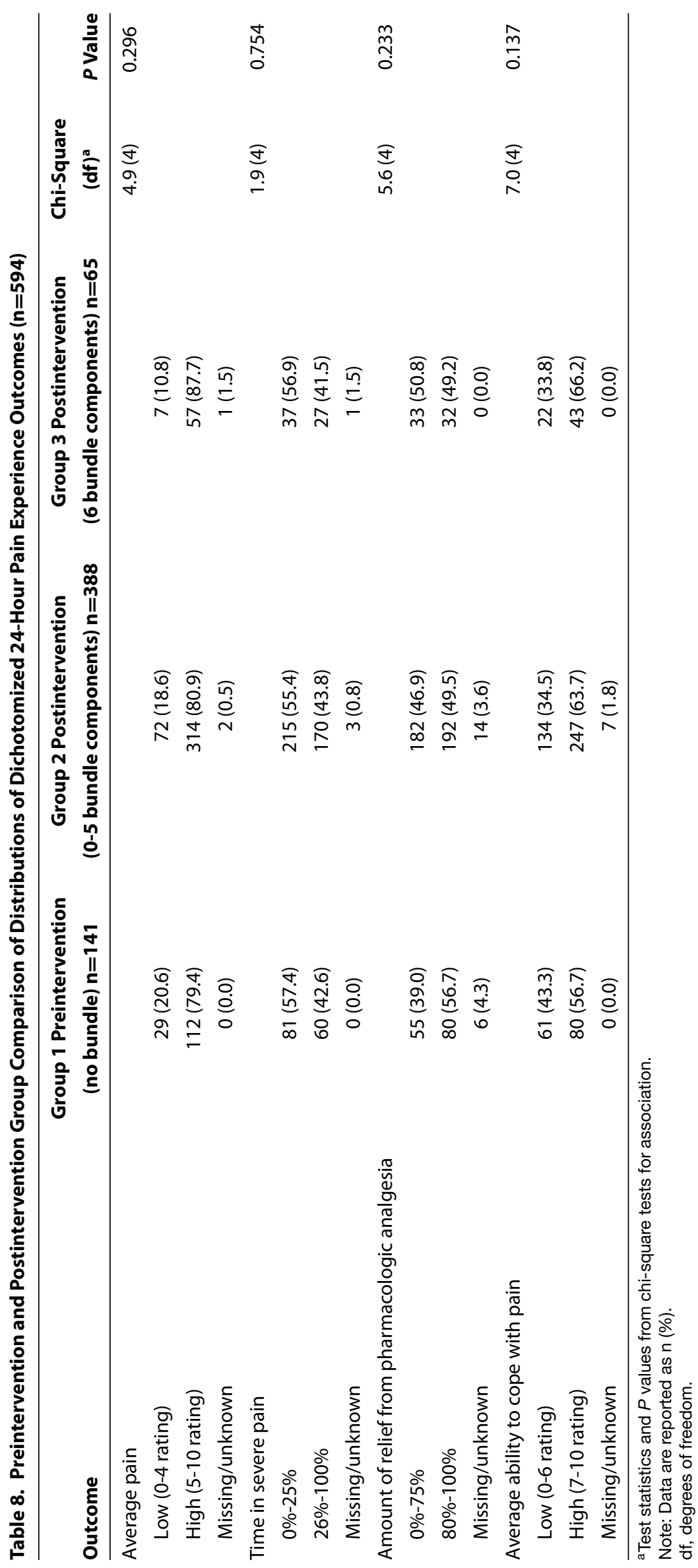


BITE Pain Therapy ${ }^{\mathrm{TM}}$

Table 9. Comparison of 24-Hour Pain Experience Outcomes by Exposure to Each Bundle Component

\begin{tabular}{|c|c|c|c|c|c|}
\hline Component & Outcome & Yes & No & Chi-Square (df) ${ }^{a}$ & $P$ Value \\
\hline \multirow[t]{12}{*}{ Component 1. Pain Education } & Average pain & & & $0.42(1)$ & 0.519 \\
\hline & Low (0-4 rating) & 18.3 & 15.3 & & \\
\hline & High (5-10 rating) & 81.7 & 84.7 & & \\
\hline & Time in severe pain & & & $0.12(1)$ & 0.729 \\
\hline & $0 \%-25 \%$ & 56.7 & 54.7 & & \\
\hline & $26 \%-100 \%$ & 43.3 & 45.3 & & \\
\hline & Amount of relief from pharmacologic analgesia & & & $0.23(1)$ & 0.229 \\
\hline & $0 \%-75 \%$ & 47.5 & 54.8 & & \\
\hline & $80 \%-100 \%$ & 52.5 & 45.2 & & \\
\hline & Average ability to cope with pain & & & $1.04(1)$ & 0.307 \\
\hline & Low (0-6 rating) & 33.7 & 39.5 & & \\
\hline & High (7-10 rating) & 66.3 & 60.5 & & \\
\hline Component 2. Pain and Coping & Average pain & & & $2.13(1)$ & 0.144 \\
\hline \multirow[t]{11}{*}{ With Pain Assessment } & Low $(0-4$ rating) & 15.4 & 20.7 & & \\
\hline & High (5-10 rating) & 84.6 & 79.3 & & \\
\hline & Time in severe pain & & & $0.00(1)$ & 0.963 \\
\hline & $0 \%-25 \%$ & 56.4 & 56.6 & & \\
\hline & $26 \%-100 \%$ & 43.6 & 43.4 & & \\
\hline & Amount of relief from pharmacologic analgesia & & & $0.05(1)$ & 0.817 \\
\hline & $0 \%-75 \%$ & 48.4 & 49.5 & & \\
\hline & $80 \%-100 \%$ & 51.6 & 50.5 & & \\
\hline & Average ability to cope with pain & & & $0.52(1)$ & 0.472 \\
\hline & Low $(0-6$ rating $)$ & 33.5 & 36.7 & & \\
\hline & High (7-10 rating) & 66.5 & 63.3 & & \\
\hline Component 3. Structured Pain & Average pain & & & $1.49(1)$ & 0.222 \\
\hline \multirow[t]{11}{*}{ Rounds } & Low (0-4 rating) & 18.7 & 12.7 & & \\
\hline & High (5-10 rating) & 81.3 & 87.3 & & \\
\hline & Time in severe pain & & & $6.32(1)$ & 0.012 \\
\hline & $0 \%-25 \%$ & 59.1 & 42.9 & & \\
\hline & $26 \%-100 \%$ & 40.9 & 57.1 & & \\
\hline & Amount of relief from pharmacologic analgesia & & & $2.76(1)$ & 0.097 \\
\hline & $0 \%-75 \%$ & 47.0 & 57.8 & & \\
\hline & $80 \%-100 \%$ & 53.0 & 42.2 & & \\
\hline & Average ability to cope with pain & & & $6.10(1)$ & 0.014 \\
\hline & Low (0-6 rating) & 32.6 & 47.9 & & \\
\hline & High (7-10 rating) & 67.4 & 52.1 & & \\
\hline Component 4. Whiteboard & Average pain & & & $2.69(1)$ & 0.101 \\
\hline \multirow[t]{8}{*}{ Communication } & Low $(0-4$ rating) & 14.0 & 20.1 & & \\
\hline & High (5-10 rating) & 86.0 & 79.9 & & \\
\hline & Time in severe pain & & & $0.06(1)$ & 0.808 \\
\hline & $0 \%-25 \%$ & 55.6 & 56.8 & & \\
\hline & $26 \%-100 \%$ & 44.4 & 43.2 & & \\
\hline & Amount of relief from pharmacologic analgesia & & & $2.43(1)$ & 0.119 \\
\hline & $0 \%-75 \%$ & 53.4 & 45.8 & & \\
\hline & $80 \%-100 \%$ & 46.6 & 54.2 & & \\
\hline
\end{tabular}


Rice, $K L$

Table 9. Continued

\begin{tabular}{|c|c|c|c|c|c|}
\hline Component & Outcome & Yes & No & Chi-Square (df) ${ }^{a}$ & $P$ Value \\
\hline & Average ability to cope with pain & & & $0.29(1)$ & 0.593 \\
\hline & Low (0-6 rating) & 33.3 & 35.8 & & \\
\hline & High (7-10 rating) & 66.7 & 64.2 & & \\
\hline Component 5. Pharmacologic & Average pain & & & $3.78(1)$ & 0.052 \\
\hline \multirow[t]{11}{*}{ Analgesia } & Low (0-4 rating) & 18.3 & 0.0 & & \\
\hline & High (5-10 rating) & 81.7 & 100.0 & & \\
\hline & Time in severe pain & & & $0.07(1)$ & 0.788 \\
\hline & $0 \%-25 \%$ & 56.2 & 52.9 & & \\
\hline & $26 \%-100 \%$ & 43.8 & 47.1 & & \\
\hline & Amount of relief from pharmacologic analgesia & & & $1.16(1)$ & 0.282 \\
\hline & $0 \%-75 \%$ & 48.8 & 62.5 & & \\
\hline & $80 \%-100 \%$ & 51.2 & 37.5 & & \\
\hline & Average ability to cope with pain & & & $1.26(1)$ & 0.262 \\
\hline & Low $(0-6$ rating $)$ & 33.9 & 47.1 & & \\
\hline & High (7-10 rating) & 66.1 & 52.9 & & \\
\hline Component 6. Nonpharmacologic & Average pain & & & $0.71(1)$ & 0.399 \\
\hline \multirow[t]{11}{*}{ Therapy Menu } & Low (0-4 rating) & 15.9 & 19.0 & & \\
\hline & High (5-10 rating) & 84.1 & 81.0 & & \\
\hline & Time in severe pain & & & $0.26(1)$ & 0.613 \\
\hline & $0 \%-25 \%$ & 58.0 & 55.6 & & \\
\hline & $26 \%-100 \%$ & 42.0 & 44.4 & & \\
\hline & Amount of relief from pharmacologic analgesia & & & $0.24(1)$ & 0.626 \\
\hline & $0 \%-75 \%$ & 50.3 & 47.9 & & \\
\hline & $80 \%-100 \%$ & 49.7 & 52.1 & & \\
\hline & Average ability to cope with pain & & & $3.21(1)$ & 0.073 \\
\hline & Low (0-6 rating) & 29.7 & 37.9 & & \\
\hline & High (7-10 rating) & 70.3 & 62.1 & & \\
\hline
\end{tabular}

Test statistics and $P$ values from chi-square tests for association.

Notes: Data are reported as percentages. Bold denotes statistical significance.

ity of participants in all 3 groups reported higher ability to cope with pain (7-10 rating) vs low ability (0-6 rating), both postintervention groups had slightly more reports of higher ability to cope compared to the preintervention group. While the nonpharmacologic menu options were included as a bundle component because of their potential impact on coping with pain, many factors contribute to an individual's ability to cope with pain. Factors such as spiritual beliefs and prior experience with using distraction in dealing with pain may have impacted responses to this question by participants in all 3 groups. However, information regarding prior knowledge and/or utilization of nonpharmacologic adjunctive therapies was not measured in the preintervention or postintervention groups. Hence, we were unable to determine whether our study provided participants with a first encounter with nonpharmacologic pain management strategies.

Although the BITE Pain Therapy ${ }^{\mathrm{TM}}$ 6-component bundle failed to impact any of the 24-hour pain experience outcomes, one individual bundle component did have an impact. Interestingly, the only bundle component associated with significantly less time in severe pain and higher ability to cope with pain was structured pain rounds. The frequent nurse/patient interaction facilitated by structured pain rounds may result in better pain management. Mitchell et al synthesized the evidence of 16 studies examining the effect of hourly rounding on patient satisfaction with nursing care. ${ }^{55}$ They concluded that despite little consistency in how hourly rounding is measured, moderate-strength evidence indicates that hourly rounding programs improved patients' perception of nursing responsiveness to requests for assistance. In addition, results from an hourly rounding best-practice implementation project on a 28-bed medical surgical unit showed a $5 \%$ increase in nurse communication and an $11 \%$ increase in pain management scores when the hourly rounding compliance rate increased to $64 \%$ from zero at baseline. ${ }^{56}$ Hence, frequent rounding about pain that promotes nursing responsiveness to patient needs may have contributed to increasing the perception of less time in severe pain and a higher ability to cope with pain. 
However, structured pain rounds did not have a relationship with participants' reports of less time in severe pain or lower average 24-hour pain scores. Despite reports by Jensen et $\mathrm{al}^{53}$ regarding the validity of 24 -hour pain score recall, challenges in accurately capturing patients' perceptions of postoperative pain using the faces scale exist. Anecdotally, many patients struggle with using the 0-10 numeric scale to communicate their level of pain, particularly when they are aware that a higher score might get them a stronger medication. Similarly, nurses may discount patients' reported pain scores that can lead to undertreatment or overtreatment of pain. ${ }^{51}$ Others have suggested that using a numeric rating scale that integrates a functional assessment of pain-related impact on activities may be a more appropriate measure of patients' self-reported pain. ${ }^{57}$ Clearly, opportunities exist in identifying effective strategies to comprehensively target pain management and in adopting reliable and valid multidimensional outcome measures to drive quality improvement.

Even though the findings from this study support that the BITE Pain Therapy ${ }^{\mathrm{TM}}$ bundled intervention improved participants' perception of pain care quality, the intervention adherence did not support sustainability of the unit-based project. Project sustainability requires continued use of intervention components with sufficient intensity to sustain achievement of program goals and outcomes. ${ }^{58,59}$ Therefore, identifying pragmatic methods to both measure adherence and capture facilitators and barriers to intervention fidelity is critical. In this study, intervention adherence was measured using patient recall for a 24-hour period rather than realtime methods to capture bundle component adherence and patient-related responses to individual bundle components. Although multiple strategies were used to improve unit-based intervention adherence-weekly communication of adherence rates, communication huddles, and soliciting information about adherence facilitators and obstaclesseveral factors during the 30-month intervention period contributed to failed intervention fidelity: changes in unit nursing leadership, high nurse turnover, and nurses' perception of increased burden associated with delivering nonpharmacologic menu options. The findings of a qualitative study describing nurse leaders' perceptions of facilitators and obstacles to unit-based pain improvement projects are similar to what we uncovered. ${ }^{60}$ Tavernier and colleagues ${ }^{60}$ concluded that sustainable improvement related to pain management projects required overcoming the pervasive barriers of dynamic organizational change and lack of staff involvement.

\section{LIMITATIONS}

Major limitations of the study are the failure of intervention fidelity, a sample from surgical units from one facility, and a sampling plan that limited recruitment to one day each month to capture the primary endpoint of a unit-based intervention study. In addition, data were not collected on the specific nonpharmacologic menu options selected and whether the participant perceived a benefit.

\section{IMPLICATIONS}

The BITE Pain Therapy ${ }^{\mathrm{TM}}$ intervention is pragmatic and can be easily tailored to include nonpharmacologic therapies that are low cost, easily accessible, and acceptable to a variety of culturally diverse populations in different acute care settings. Since the inception of our project, the American Pain Society (APS) published guidelines for the management of postoperative patients ${ }^{61}$ that includes recommendations for behavioral/cognitive therapies such as guided imagery and music therapy as adjuncts to multimodal pharmacologic pain management. In addition, the Joint Commission ${ }^{10}$ revised pain assessment and management standards effective January 1, 2018, to include involving patients in developing pain management plans that include setting realistic expectations and measurable goals and providing nonpharmacologic options for inpatient pain treatment. All 6 bundle components in our patient-centered, multidisciplinary BITE Pain Therapy ${ }^{\mathrm{TM}}$ intervention address the APS guidelines and Joint Commission recommendations that focus on effective pain management. All of the BITE Pain Therapy ${ }^{\mathrm{TM}}$ bundle components are congruent with the standard of nursing care. Offering adjunctive complementary therapy options such as aromatherapy, distraction activities (ie, puzzles, games), and individual handheld massagers is feasible on medical surgical units. In addition, opportunities to provide pet therapy and music therapy may be available by using institutional volunteer services.

Our findings identified that postintervention participants with acute pain alone, irrespective of whether they received all bundle components or not, reported less time in severe pain and more relief from pharmacologic analgesia. This finding is consistent with the findings of the National Database of Nursing Quality Indicators study ${ }^{62}$ and suggests that healthcare providers do a better job with acute pain in the inpatient setting. Therefore, interprofessional education about comprehensively assessing and effectively managing both acute and chronic pain in the hospitalized adult is needed.

Finally, additional research is warranted to replicate this study at other types of inpatient facilities and in different patient populations. Studies should be designed to test care delivery processes that deliver the intervention without increasing nurses' burden of work. In addition, studies should explore strategies to assist healthcare providers to identify which patients will benefit from the bundled pain management strategies and/or individual bundle components.

\section{CONCLUSION}

Findings from this study support that medical surgical patients participating in this study who received all 6 components of the BITE Pain Therapy ${ }^{\mathrm{TM}}$ intervention reported significantly higher levels of perceived pain care quality compared to those who did not receive all bundle components. Therefore, a bundled approach to pain management may be more beneficial than unstandardized strategies. Challenges exist in implementing the complete bundle to all patients in pain.

\section{ACKNOWLEDGMENTS}

The research methods and limited findings from this study were disseminated as a podium presentation, "BITE Pain Therapy: Bundling of Interventions to Enhance Pain Care Quality," at the 2018 American Nurses Association Quality 
and Innovation Summit in Orlando, FL in March 2018. The authors have no financial or proprietary interest in the subject matter of this article.

\section{REFERENCES}

1. Institute of Medicine (US) Committee on Advancing Pain Research, Care, and Education. Relieving Pain in America: $A$ Blueprint for Transforming, Prevention, Care, Education, and Research. Washington, DC: The National Academies Press; 2011.

2. Gaskin DJ, Richard P. The economic costs of pain in the United States. J Pain. 2012 Aug;13(8):715-724. doi: 10.1016/j.jpain.2012.03.009.

3. HCAHPS three-state pilot study analysis results. CAHPS II Investigators \& AHRQ. www.cms.gov/Medicare/QualityInitiatives-Patient-Assessment-Instruments/Hospital Qualitylnits/downloads/Hospital3State_Pilot_Analysis_ Final200512.pdf. Published December 22, 2003. Accessed November 1, 2018.

4. Glowacki D. Effective pain management and improvements in patients' outcomes and satisfaction. Crit Care Nurse. 2015 Jun;35(3):33-41; quiz 43. doi: 10.4037/cen2015440.

5. Simmons SF, Schnelle JF, Saraf AA, et al. Pain and satisfaction with pain management among older patients during the transition from acute to skilled nursing care. Gerontologist. 2016 Dec;56(6):1138-1145. doi: 10.1093/geront/gnv058.

6. Hanna MN, González-Fernández M, Barrett AD, Williams KA, Pronovost $\mathrm{P}$. Does patient perception of pain control affect patient satisfaction across surgical units in a tertiary teaching hospital? Am J Med Qual. 2012 Sep-Oct;27(5):411-416. doi: $10.1177 / 1062860611427769$.

7. Voscopoulos C, Lema M. When does acute pain become chronic. Br J Anaesth. 2010 Dec;105 Suppl 1:i69-i85. doi: $10.1093 / \mathrm{bja} / \mathrm{aeq} 323$.

8. Apfelbaum JL, Chen C, Mehta SS, Gan TJ. Postoperative pain experience: results from a national survey suggest postoperative pain continues to be undermanaged. Anesth Analg. 2003 Aug;97(2):534-540.

9. Hospital value-based purchasing. Centers for Medicare and Medicaid Services. ICN 907664. www.cms.gov/Outreach-andEducation/Medicare-Learning-Network-MLN/MLNProducts/ downloads/Hospital_VBPurchasing_Fact_Sheet_ICN907664. pdf. Published September 2017. Accessed November 1, 2018.

10. Joint Commission. Joint Commission enhances pain assessment and management requirements for accredited hospitals. The Joint Commission Perspectives': The Official Newsletter of The Joint Commission. 37(7). www. jointcommission.org/assets/1/18/Joint_Commission_Enhances _Pain_Assessment_and_Management_Requirements_for _Accredited_Hospitals1.PDF. Published July 2017. Accessed November 1, 2018.

11. Sinatra R. Causes and consequences of inadequate management of acute pain. Pain Med. 2010 Dec;11(12):1859-1871. doi: 10.1111/j.1526-4637.2010.00983.x.

12. Carver CS. Stress, coping, and health. In: Friedman HS, Silver RC, eds. Foundations of Health Psychology. New York, NY: Oxford University Press; 2007:117-144.

13. Koolhaas JM, Bartolomucci A, Buwalda B, et al. Stress revisited: a critical evaluation of the stress concept. Neurosci Biobehav Rev. 2011 Apr;35(5):1291-1301. doi: 10.1016/j.neubiorev.2011.02.003.

14. Oxford Centre for Evidence-Based Medicine - Levels of Evidence. Centre for Evidence Based Medicine. www.cebm.net/ 2009/06/oxford-centre-evidence-based-medicine-levels- evidence-march-2009/. Published March 2009. Accessed November 1, 2018.

15. Goldberg GR, Morrison RS. Pain management in hospitalized cancer patients: a systematic review. J Clin Oncol. 2007 May 1;25(13):1792-1801. doi: 10.1200/JCO.2006.07.9038.

16. Crowe L, Chang A, Fraser J, Gaskill D, Nash R, Wallace K. Systematic review of the effectiveness of nursing interventions in reducing or relieving post-operative pain. Int J Evid Based Healthc. 2008 Dec;6(4):396-430. doi: 10.1111/j.1744-1609.2008.00113.x.

17. Castillo-Bueno MD, Moreno-Pina JD, Martínez-Puente MV, et al. Effects of nursing interventions for adult patients experiencing chronic pain: a systematic review. JBI Libr Syst Rev. 2010;8(28):1112-1168.

18. Cole LC, LoBiondo-Wood G. Music as adjuvant therapy in control of pain symptoms in hospitalized adults: a systematic review. Pain Manag Nurs. 2014 Mar;15(1):406-425. doi: 10.1016/j.pmn.2012.08.010.

19. Sjöling M, Nordahl G, Olofsson N, Asplund K. The impact of preoperative information on state anxiety, postoperative pain and satisfaction with pain management. Patient Educ Couns. 2003 Oct;51(2):169-176.

20. Garra D, Singer AJ, Leno R, et al. Heat or cold packs for neck and back strain: a randomized controlled trial of efficacy. Acad Emerg Med. 2010 May;17(5):484-489. doi: 10.1111/j.1553-2712.2010.00735.x.

21. Gutgsell KJ, Schluchter M, Margevicius S, et al. Music therapy reduces pain in palliative care patients: a randomized controlled trial. J Pain Symptom Manage. 2013 May;45(5):822-831. doi: 10.1016/j.jpainsymman.2012.05.008.

22. Hausmann LR, Parks A, Youk AO, Kwoh CK. Reduction of bodily pain in response to an online positive activities intervention. $J$ Pain. 2014 May;15(5):560-567. doi: 10.1016/j.jpain.2014.02.004.

23. Jameson E, Trevena J, Swain N. Electronic gaming as pain distraction. Pain Res Manag. 2011 Jan-Feb;16(1):27-32.

24. Olapour A, Behaeen K, Akhondzadeh R, Soltani F, Al Sadat Razavi F, Bekhradi R. The effect of inhalation of aromatherapy blend containing lavender essential oil on cesarian postoperative pain. Anesth Pain Med. 2013 Summer;3(1):203-207. doi: 10.5812/aapm.9570.

25. Olrich T, Kalman M, Nigolian C. Hourly rounding: a replication study. Medsurg Nurs. 2012 Jan-Feb;21(1):23-36.

26. Marcus DA, Bernstein CD, Constantin JM, Kunkel FA, Breuer $P$, Hanlon RB. Animal-assisted therapy at an outpatient pain management clinic. Pain Med. 2012 Jan;13(1):45-57. doi: 10.1111/j.1526-4637.2011.01294.x.

27. Sauaia A, Min SJ, Leber C, Erbacher K, Abrams F, Fink R. Postoperative pain management in elderly patients: correlation between adherence to treatment guidelines and patient satisfaction. J Am Geriatr Soc. 2005 Feb;53(2):274-282. doi: 10.1111/j.1532-5415.2005.53114.x.

28. Archer KR, Castillo RC, Wegener ST, Abraham CM, Obremskey WT. Pain and satisfaction in hospitalized trauma patients: the importance of self-efficacy and psychological distress. J Trauma Acute Care Surg. 2012 Apr;72(4):1068-1077. doi: 10.1097/TA.0b013e3182452df5.

29. Baldacchino D, Torskenaes K, Kalfoss M, et al. Spiritual coping in rehabilitation-a comparative study: part 2. Br J Nurs. 2013 Apr 11-24;22(7):402-408. doi: 10.12968/bjon.2013.22.7.402.

30. Chan S, Hadjistavropoulos T, Carleton RN, Hadjistavropoulos $\mathrm{H}$. Predicting adjustment to chronic pain in older adults. Can J Behav Sci. 2012 Jul;44(3):192-199. doi: 10.1037/a0028370.

31. Heutink M, Post MW, Overdulve CW, et al. Which pain coping strategies and cognitions are associated with outcomes of a 
cognitive behavioral intervention for neuropathic pain after spinal cord injury? Top Spinal Cord Inj Rehabil. 2013

Fall;19(4):330-340. doi: 10.1310/sci1904-330.

32. Ramírez-Maestre C, Esteve R, López AE. Cognitive appraisal and coping in chronic pain patients. Eur J Pain. 2008 Aug;12(8):749-756. doi: 10.1016/j.ejpain.2007.11.004.

33. Stoffel M, Reis D, Schwarz D, Schröder A. Dimensions of coping in chronic pain patients: factor analysis and cross-validation of the German version of the Coping Strategies Questionnaire (CSQ-D). Rehabil Psychol. 2013 Nov;58(4):386-395. doi: $10.1037 / a 0034358$.

34. Phelan C. An innovative approach to targeting pain in older people in the acute care setting. Contemp Nurse. 2010 Jun;35(2):221-233. doi: 10.5172/conu.2010.35.2.221.

35. Naveh P, Leshem R, Dror YF, Musgrave CF. Pain severity, satisfaction with pain management, and patient-related barriers to pain management in patients with cancer in Israel. Oncol Nurs Forum. 2011 Jul;38(4):E305-E313. doi: 10.1188/11.ONF.E305-E313.

36. Dezutter J, Wachholtz A, Corveleyn J. Prayer and pain: the mediating role of positive re-appraisal. J Behav Med. 2011 Dec;34(6):542-549. doi: 10.1007/s10865-011-9348-2.

37. Thompson A, Wilson M, James T, Symbal J, Izumi S. Feasibility study to implement nurse-delivered massage for pain management. J Hosp Palliat Nurs. 2013 Oct;15(7):403-409. doi: 10.1097/NJH.0b013e31829e0ed2.

38. Vaajoki A, Kankkunen $P$, Pietilä A, Kokki $H$, Vehviläinen-Julkunen $K$. The impact of listening to music on analgesic use and length of hospital stay while recovering from laparotomy. Gastroenterol Nurs. 2012 Jul-Aug;35(4):279-284. doi: 10.1097/SGA.0b013e3182608fc1.

39. Wang HL, Keck JF. Foot and hand massage as an intervention for postoperative pain. Pain Manag Nurs. 2004 Jun;5(2):59-65.

40. Potter C, Dunton N, Beck S. Pain care quality and RN staffing characteristics among United States adult medical, surgical units. J Pain. 2013 Apr;14(4):S39. doi: 10.1016/j.jpain.2013.01.454.

41. Berenholtz SM, Pham JC, Thompson DA, et al. Collaborative cohort study of an intervention to reduce ventilator-associated pneumonia in the intensive care unit. Infect Control Hosp Epidemiol. 2011 Apr;32(4):305-314. doi: 10.1086/658938.

42. Bird D, Zambuto A, O'Donnell C, et al. Adherence to ventilator-associated pneumonia bundle incidence of ventilator-associated pneumonia in the surgical intensive care unit. Arch Surg. 2010 May;145(5):465-470. doi: 10.1001/archsurg.2010.69.

43. Paul R, Melendez E, Stack A, Caprano A, Monuteaux M, Neuman MI. Improving adherence to PALS septic shock guidelines. Pediatrics. 2014 May;133(5):e1358-e1366. doi: 10.1542/peds.2013-3871.

44. van Zanten AR, Brinkman S, Arbous MS, Abu-Hanna A, Levy MM, de Keizer NF; Netherlands Patient Safety Agency Sepsis Expert Group. Guideline bundles adherence and mortality in severe sepsis and septic shock. Crit Care Med. 2014 Aug;42(8):1890-1898. doi: 10.1097/CCM.0000000000000297.

45. Beck SL, Towsley GL, Berry PH, Brant JM, Smith EM. Measuring the quality of care related to pain management: a multiple-method approach to instrument development. Nurs Res. 2010 Mar-Apr;59(2):85-92. doi: 10.1097/NNR.0b013e3181d1a732.

46. Cleeland CS, Ryan KM. Pain assessment: global use of the Brief Pain Inventory. Ann Acad Med Singapore. 1994 Mar;23(2):129-138.
47. Pett MA, Beck SL, Guo JW, et al. Confirmatory factor analysis of the pain care quality surveys (PainCQ๑). Health Serv Res. 2013 Jun;48(3):1018-1038. doi: 10.1111/1475-6773.12014.

48. Hamlin AS, Robertson TM. Pain and complementary therapies. Crit Care Nurs Clin North Am. 2017 Dec;29(4):449-460. doi: 10.1016/j.cnc.2017.08.005.

49. Lakhan SE, Sheafer H, Tepper D. The effectiveness of aromatherapy in reducing pain: a systematic review and meta-analysis. Pain Res Treat. 2016;2016:8158693. doi: 10.1155/2016/8158693.

50. Boonstra AM, Stewart RE, Köke AJ, et al. Cut-off points for mild, moderate, and severe pain on the numeric rating scale for pain in patients with chronic musculoskeletal pain: variability and influence of sex and catastrophizing. Front Psychol. 2016 Sep 30;7:1466. doi: 10.3389/fpsyg.2016.01466.

51. Gerbershagen HJ, Rothaug J, Kalkman CJ, Meissner W. Determination of moderate-to-severe postoperative pain on the numeric rating scale: a cut-off point analysis applying four different methods. Br J Anaesth. 2011 Oct;107(4):619-626. doi: 10.1093/bja/aer195.

52. Jensen MP, Castarlenas E, Tomé-Pires C, de la Vega $R$, Sánchez-Rodríguez E, Miró J. The number of ratings needed for valid pain assessment in clinical trials: replication and extension. Pain Med. 2015 Sep;16(9):1764-1772. doi: $10.1111 /$ pme.12823.

53. Jensen MP, Mardekian J, Lakshminarayanan M, Boye ME. Validity of 24-h recall ratings of pain severity: biasing effects of "peak" and "end" pain. Pain. 2008 Jul 15;137(2):422-427. doi: 10.1016/j.pain.2007.10.006.

54. Bolton JE, Humphreys BK, van Hedel HJ. Validity of weekly recall ratings of average pain intensity in neck pain patients. $J$ Manipulative Physiol Ther. 2010 Oct;33(8):612-617. doi: 10.1016/j.jmpt.2010.08.009.

55. Mitchell MD, Lavenberg JG, Trotta RL, Umscheid CA. Hourly rounding to improve nursing responsiveness: a systematic review. J Nurs Adm. 2014 Sep;44(9):462-472. doi: 10.1097/NNA.0000000000000101.

56. Daniels JF. Purposeful and timely nursing rounds: a best practice implementation project. JBI Database System Rev Implement Rep. 2016 Jan;14(1):248-267. doi: 10.11124/jbisrir-2016-2537.

57. Buckenmaier CC 3rd, Galloway KT, Polomano RC, McDuffie M, Kwon N, Gallagher RM. Preliminary validation of the defense and veterans pain rating scale (DVPRS) in a military population. Pain Med. 2013 Jan;14(1):110-123. doi: 10.1111/j.1526-4637.2012.01516.x.

58. Lough ME, Rice KL. Transferring scientific knowledge into action at the point of care: do we have all the facts? Clin Nurs Spec. 2016 Nov/Dec;30(6):315-317. doi: $10.1097 /$ NUR.0000000000000249.

59. Shelton RC, Cooper BR, Stirman SW. The sustainability of evidence-based interventions and practices in public health and health care. Annu Rev Public Health. 2018 Apr 1;39:55-76. doi: 10.1146/annurev-publhealth-040617-014731.

60. Tavernier SS, Guo JW, Eaton J, Brant JM, Berry P, Beck SL. Context matters for nurses leading pain improvement in U.S. hospitals. Pain Manag Nurs. 2018 Oct;19(5):474-486. doi: 10.1016/j.pmn.2018.05.003.

61. Chou R, Gordon DB, de Leon-Casasola OA, et al. Management of postoperative pain: a clinical practice guideline from the American Pain Society, the American Society of Regional 
Anesthesia and Pain Medicine, and the American Society of Anesthesiologists' Committee on Regional Anesthesia,

Executive Committee, and Administrative Council. J Pain. 2016

Feb;17(2):131-157. doi: 10.1016/j.jpain.2015.12.008.
62. Beck SL, Dunton N, Berry PH, et al. Dissemination and implementation of patient-centered indicators of pain care quality and outcomes. Med Care. 2019 Feb;57(2):159-166. doi: 10.1097/MLR.0000000000001042.

This article meets the Accreditation Council for Graduate Medical Education and the American Board of Medical Specialties Maintenance of Certification competencies for Patient Care, Medical Knowledge, and Practice-Based Learning and Improvement. 